\title{
RESEARCH
}

Open Access

\section{Disease control in patients with asthma and respiratory symptoms (wheezing, cough) during sleep}

Jonathan Doenges ${ }^{1 *}$ (D) Elisabeth Kuckuck ${ }^{1}$, Werner Cassel ${ }^{1}$, Olaf Hildebrandt ${ }^{1}$, Andreas Weissflog ${ }^{2}$, Keywan Sohrabi ${ }^{3}$, Niklas Koehler ${ }^{3}$, Volker Gross ${ }^{3}$, Timm Greulich ${ }^{1}$ and Ulrich Koehler ${ }^{\text {** }}$

\begin{abstract}
Introduction: The Global Initiative for Asthma (GINA)-defined criteria for asthma control include questions about daytime symptoms, limitation of activity, nocturnal symptoms, need for reliever treatment and patients' satisfaction. Patients with nocturnal symptoms like wheezing and cough often suffer from lower sleep quality and impaired daytime performance. The lack of an appropriate method for standardized and objective monitoring of respiratory symptoms leads to difficulties in asthma management. The aim of this study is to present a new method for automated wheeze and cough detection during sleep and to assess the actual level of asthma control by the Asthma Control Test (ACT).
\end{abstract}

Methods: Respiratory symptoms like wheezing and cough were recorded with the LEOSound-Monitor for one night in 55 asthmatic patients in their individual domestic setting. Patients were asked to assess their level of asthma subjectively with the ACT. The study consisted of 37 women and 18 men, with a mean age of 41 years, and a mean BMl of $27 \mathrm{~kg} / \mathrm{m}^{2}$. Most of the patients had been taking an ICS/LABA combination and would resort to a SABA as their rescue medication.

Results: $60 \%$ of the participants were classed as having controlled, and $40 \%$ were classed as having partially- or uncontrolled asthma. During sleep wheezing was found in 8 of the 55 asthma patients (14.5\%) and coughing was found in 30 patients (54.5\%). The median ACT score in wheezing-patients was 14, while in non-wheezing patients it was 21. Uncontrolled asthma was found in 6 of the 8 wheezing-patients. Coughing versus non-coughing patients did not show a significant difference in the ACT-score (20, 22 respectively).

Conclusion: Wheezing is a sign of uncontrolled asthma. The ACT-score in wheezing patients is worse compared to patients without wheezing. LEOSound proofed to be a useful tool in providing an objective evaluation of respiratory symptoms, like coughing and wheezing. In clinical practice, this may allow an improvement in asthma therapy.

Keywords: Asthma, Wheezing, Cough, Long-term monitoring of respiratory sounds, Asthma control test

\footnotetext{
*Correspondence: jonathan.doenges@gmail.com; koehleru@med.uni-

marburg.de

'Department of Internal Medicine, Division of Pneumology, Intensive Care and Sleep Medicine, Hospital of the University of Marburg, Baldingerstrasse 1, 35033 Marburg, Germany

Full list of author information is available at the end of the article
}

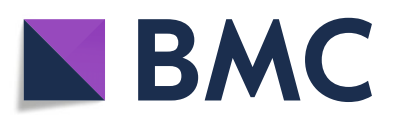

(- The Author(s). 2020 Open Access This article is licensed under a Creative Commons Attribution 4.0 International License, which permits use, sharing, adaptation, distribution and reproduction in any medium or format, as long as you give appropriate credit to the original author(s) and the source, provide a link to the Creative Commons licence, and indicate if changes were made. The images or other third party material in this article are included in the article's Creative Commons licence, unless indicated otherwise in a credit line to the material. If material is not included in the article's Creative Commons licence and your intended use is not permitted by statutory regulation or exceeds the permitted use, you will need to obtain permission directly from the copyright holder. To view a copy of this licence, visit http://creativecommons.org/licenses/by/4.0/. The Creative Commons Public Domain Dedication waiver (http://creativecommons.org/publicdomain/zero/1.0/) applies to the data made available in this article, unless otherwise stated in a credit line to the data. 


\section{Introduction}

Bronchial asthma is one of the most common chronic diseases affecting worldwide about 300 Million people of all ages and of all ethnic backgrounds. Furthermore, a lack of optimal medical care is described as a factor of preventable deaths [1]. Medication management of asthma is based on the degree of asthma control. GINAdefined criteria for asthma control include questions about daytime symptoms, limitation of activity, nocturnal symptoms, need for reliever treatment and patient satisfaction [2]. Effective asthma control is necessary to prevent exacerbations and worsening of lung function. Standardised and validated questionnaires such as the Asthma Control Test (ACT) assess the level of asthma control [3]. It classifies asthma as "controlled", "partially controlled" or "uncontrolled" within the last 4 weeks.

Multicentre studies like REALISE and AIRE provide information about effectiveness and adherence to medication over nearly 15 years. Asthma is still poorly controlled in more than $50 \%$ of patients despite the availability of very effective drugs [4-10]. In addition, acoustic long-term monitoring of respiratory sounds is an important addition to the diagnostic spectrum, because symptoms like wheezing and cough are objectively measurable, especially during sleep $[11,12]$. The patient's perception of disease and the reality diverge considerably sometimes [13]. A large proportion of asthma patients rate their disease control as good when in fact it is not. Therefore, an objective evaluation of the respiratory symptoms in patients with asthma may have a huge clinical impact by classifying the asthma control status more accurately. Consequently, medication and therapy of patients with asthma could be improved.

The aim of this study was i.). Analyse the patients' judgement of asthma control and ii.). Monitor respiratory symptoms like wheezing and cough during sleep.

\section{Methods}

We subselected 55 patients from a previous, not yest published, study, which focused on the phenotypes of eosinophilic and non-eosinophilic asthma. Inclusion criteria were an age between 18 and 65 years as well as a diagnosis of bronchial asthma. In addition, we limited the patients' nicotine abuse to a maximum of 10 pack years. Informed written consent to participate in the study was obtained from every patient. Exclusion criteria were the presence of any acute lung disease (e.g. bronchitis) or severe infectious disease (e.g. tuberculosis, etc.). Before the overnight study took place, the measurement procedure was explained to the patient, including the positioning of the three microphones. The microphones and the device were designed to ensure maximum comfort, which resulted in a high compliance of the participants. The duration of the overnight monitoring was between 7 and $9 \mathrm{~h}$. The data collection took place between September 2018 and October 2019. Besides, the patients were asked to assess their level of asthma with the ACT. The study was approved by the Ethics Committee of the Philipps University of Marburg (Az.: 94/18).

\section{Longterm recording of respiratory sounds - LEOSound}

The LEOSound Lung-Sound-Monitor is a mobile device validated for automatic long-term recording and analysis of normal and adventitious respiratory sounds like cough and wheezing in adults and children [11]. The system automatically detects cough and wheezing for up to $24 \mathrm{~h}$ and can be used either in the hospital or at the patient's home. Sound is recorded with three bio-acoustical sensors, one placed at the trachea and two placed on the patients' back (Fig. 1). In addition, an ambient microphone is integrated in the LEOSound device. It is thus possible to differentiate lung sounds from speech and other ambient sounds. The devices were programmed in advance for every patient. The associated software contains automated algorithms for cough and wheezing detection (Fig. 2). The LEOSound-Monitor was validated in various clinical studies, and showed a sensitivity and specifity of $80-95 \%$ [14].

\section{Patients}

Thirty-seven women and 18 men, aged between 20 and 67 years, were included. The average age of the participants was 41 years with a mean BMI of $26.5 \mathrm{~kg} / \mathrm{m}^{2}$ (standard deviation \pm 6.1 ). Table 1 gives an overview of the patients' characteristics. There was no restriction in medication. Most of the included patients had been taking an ICS/LABA combination and would have resorted to a SABA as their rescue medication (see Table 2).

\section{Asthma control test (ACT)}

Asthma control was determined using a validated questionnaire (Asthma Control Test, ACT) [3]. We decided to choose the ACT cut of scores that GINA referred to in its main report [2]. This resulted in a more balanced data set. The scoring system reflects the degree of asthma control during the previous month, and is based on five questions: 1) shortness of breath, 2) awakenings due to asthma symptoms, 3) frequency of reliever medication use, 4) impairment at work or school and 5) patient's own rating of control. The patient rates each criterion with a score from 1 (worst) to 5 (best). 20-25 points represent an asthma well under control (ACT-1), a score of 16-19 points indicates a partially controlled asthma (ACT-2), whereas 15 or less points indicate an uncontrolled asthma (ACT-3). 

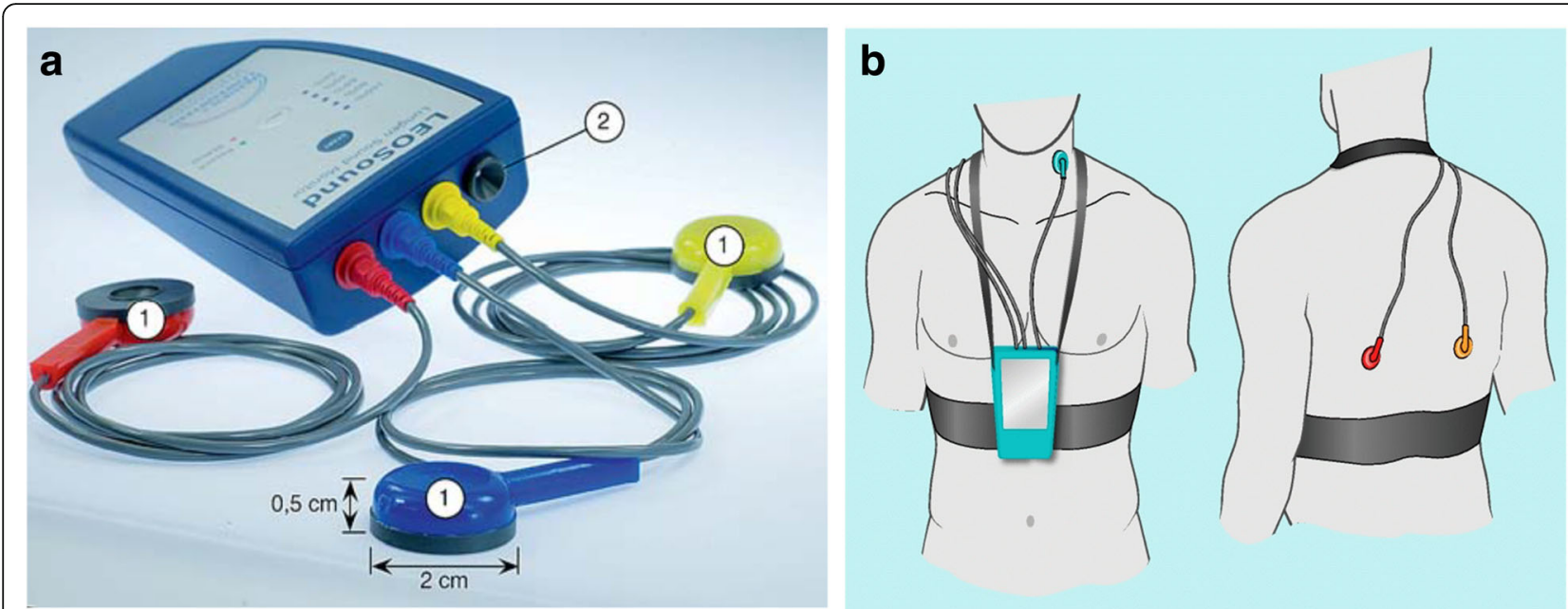

Fig. 1 a LEOSound-recorder with three body microphones (labelled 1) and one ambient microphone (labelled 2). b Illustration of the recorder and microphone placement during the observation. The figure depicts one tracheal microphone and two bronchial microphones [11]

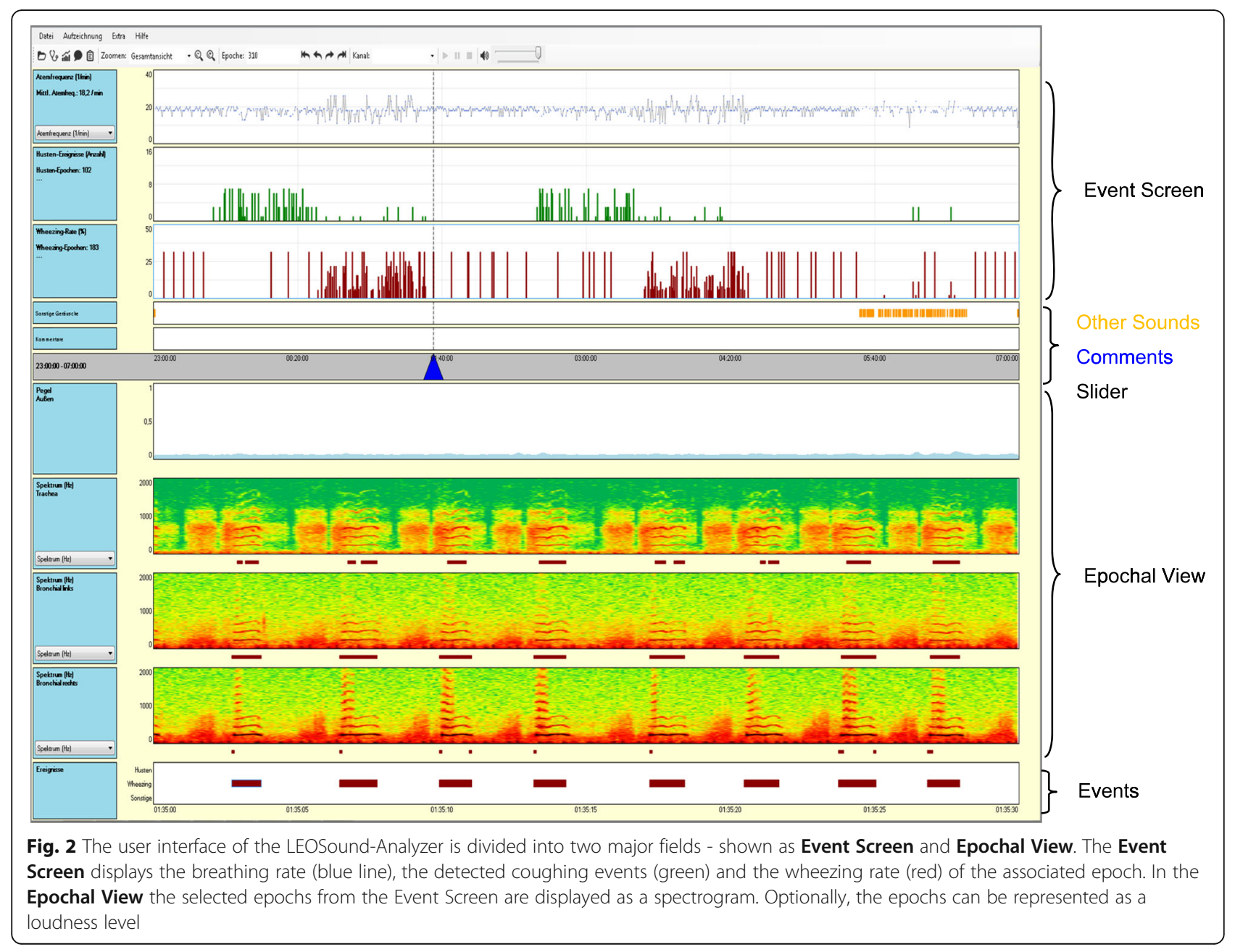


Table 1 Anthropometric data of study cohort $(n=55)$

\begin{tabular}{lll}
\hline & n/N or Average \pm SD & Min - Max \\
\hline Sex [\% female] & $37 / 55(67.3)$ & \\
Age [years] & $41.0 \pm 13.7$ & $20-67$ \\
Weight $[\mathrm{kg}]$ & $78.9 \pm 21.2$ & $51-136$ \\
Height $[\mathrm{cm}]$ & $172 \pm 12$ & $154-200$ \\
BMl $\left[\mathrm{kg} / \mathrm{m}^{2}\right]$ & $26.5 \pm 6.1$ & $17.4-47.1$ \\
Smoker $[\mathrm{PY}]$ & $1.8 \pm 3.2$ & $0-10$ \\
\hline
\end{tabular}

\section{Statistical methods}

Statistical analysis was performed using IBM SPSS Statistics Version 25 (IBM GmbH). The KolmogorovSmirnov-Test was used to test for normal distribution. Where the normal distribution hypothesis was rejected, non parametric methods were used for both descriptive and interferential statistical calculations. As coughing and wheezing variables were not found to be normally distributed, median and range were used to describe all parameters. For some normally distributed variables such as age, average and standard deviation $(\mathrm{AVG} \pm \mathrm{SD})$ were reported as well.

Kruskall-Wallis one-way analysis of variance was used to compare the three Asthma Control groups. A statistically significant test result was obtained, if $p \leq 0.05$.

The Mann-Whitney test was also used to compare wheezing and non-wheezing patients and coughing and non-coughing patients.

\section{Results}

$60 \%$ of the patients were classed as having controlled asthma, and $40 \%$ of the patients as having partially- or uncontrolled asthma. In 33 patients the asthma status was classified as ACT-1, in 10 patients as ACT-2 and in 12 patients as ACT-3. Table 3 shows the patients' parameters depending on their asthma control status.

\section{Wheezing}

Lung sound recordings showed wheezing during sleep in 8 out of 55 patients $(14.5 \%)$ with a median duration of

Table 2 Medication used within the study cohort

\begin{tabular}{ll}
\hline Medication & n/N (\%) \\
\hline ICS/LABA & $37 / 55(67,3)$ \\
ICS solo & $7 / 55(12,7)$ \\
LAMA & $8 / 55(14,5)$ \\
SABA & $39 / 55(70,9)$ \\
SAMA & $4 / 55(7,3)$ \\
Omalizumab & $3 / 55(5,5)$ \\
Montelukast & $7 / 55(12,7)$ \\
Mepolizumab/Benralizumab & $3 / 55(5,5)$ \\
\hline
\end{tabular}

$9.5 \mathrm{~min}$. The maximum wheezing duration was $30.5 \mathrm{~min}$. With respect to ACT, the median score of the nonwheezing group was 21 , whereas within the wheezing group the median score was 14 points. Six out of 8 wheezing patients were found in the ACT-3 Group, which means their current asthmatic status was uncontrolled. Statistical calculation showed a significant difference between the wheezing- and the non-wheezing group $(p=0.001)$. Table 4 compares the anthropometric data and the recorded LeoSound parameters between the wheezing and the non- wheezing group. Figure 3 shows the total number of wheezing patients across the different ACT-groups.

\section{Cough}

Coughing was detected during sleep in 30 patients with a median rate of 0.9 coughs per hour and a maximum of 34.3 coughs per hour. There was no significant difference between the ACT scores of coughing and noncoughing patients. However, as seen in Fig. 4, the ACT3 Group presented a higher percentage of coughing patients compared to ACT- 1 and ACT-2 Group. Table 5 compares the anthropometric data and the recorded LeoSound parameters between the coughing and the non- coughing patients.

\section{Discussion}

In this study, the monitoring of wheezing during sleep showed a significant relation to the ACT score and therefore, the subjective asthma control of patients at daytime. Patients who scored their asthma as being uncontrolled were more likely to show nocturnal wheezing symptoms compared to patients who scored their asthma as controlled. Moreover, the lung sound monitoring during sleep may even detect respiratory symptoms of which patients are unaware, as wheezing was found in one patient who scored his asthma as controlled (see Fig. 3).

Asthma is caused by a multitude of factors and has a heterogeneous set of manifestations [2]. The presentation of asthma is highly variable. Typical asthma symptoms include dyspnoea, coughing, wheezing, occasional thoracic tightness, and severe asthma attacks. Asthma patients frequently suffer from nocturnal and early morning respiratory discomfort, which is due to the chronobiological rhythm of the airway width.

Braghiroli et al. recently described the lack of research and established clinical $24 \mathrm{~h}$ monitoring of respiratory symptoms that would result in a more adequate medication therapy. Circadian variations usually cause a worsening of respiratory symptoms during sleep. Supine position and physiological changes such as vagal stimulation with an increased airway resistance are contributing factors. For this reason, Braghiroli et al. emphasized 
Table 3 Differences between anthropometric data, and parameters of LEOSound-monitoring depending on ACT status

\begin{tabular}{|c|c|c|c|c|c|c|c|}
\hline & \multicolumn{2}{|c|}{ ACT $-1(n=33)$} & \multicolumn{2}{|c|}{ ACT - $2(n=10)$} & \multicolumn{3}{|c|}{ ACT $-3(n=12)$} \\
\hline & Median & Min - Max & Median & Min - Max & Median & Min - Max & $p$-value (over all/ACT-1 vs 3) \\
\hline \multicolumn{8}{|l|}{ Collective of patients } \\
\hline Age & 34 & $20-63$ & 38 & $23-67$ & 55.5 & $30-67$ & $0.003 / 0.001$ \\
\hline Height & 172.5 & $154-200$ & 167 & 159-195 & 163.5 & 156-196 & 0.217 \\
\hline Weight & 76.5 & $52-131$ & 70 & $51-136$ & 78.5 & $55-135$ & 0.752 \\
\hline BMl & 24.8 & $17.4-36.7$ & 23.7 & $18.7-47.1$ & 26.7 & $21.8-40.8$ & 0.443 \\
\hline PY & 0 & $0-10$ & 0 & $0-10$ & 1 & $0-8$ & 0.389 \\
\hline ACT & 22 & $21-25$ & 18 & $16-20$ & 14 & $10-15$ & $<0.001 /<0.001$ \\
\hline \multicolumn{8}{|l|}{ LEOSound } \\
\hline & Median & Min - Max & Median & Min - Max & Median & Min - Max & $p$-value \\
\hline Cough epoch /hour & 0 & $0-0.8$ & 0.1 & $0-1.8$ & 0.6 & $0-4.8$ & $0.040 / 0.015$ \\
\hline Abs Quantity coughs & 0 & $0-5$ & 3 & $0-28$ & 10 & $0-275$ & 0.051 \\
\hline Quantity of cough /h & 0 & $0-25$ & 0.4 & $0-3.5$ & 1.3 & $0-34.4$ & $0.049 / 0.017$ \\
\hline Wheezing phases & 0 & $0-1$ & 0 & $0-3$ & 0.5 & $0-5$ & $<0.001 /<0.001$ \\
\hline Wheez. epoch/hour & 0 & $0-1$ & 0 & $0-7.6$ & 0.8 & $0-7.3$ & $<0.001 /<0.001$ \\
\hline Wheez. durat. [min] & 0 & $0-8.9$ & 0 & $0-30.5$ & 3 & $0-29$ & $<0.001 /<0.001$ \\
\hline Wheez. duration [\%] & 0 & $0-0.9$ & 0 & $0-8.1$ & 0.8 & $0-6.5$ & $<0.001 /<0.001$ \\
\hline
\end{tabular}

Statistically significant $p$-values are bold

the significance and importance of new digital tools to provide objective and long-term evaluation of respiratory symptoms like cough and wheezing in order to improve therapeutic choice [15].

Wheezes are high-pitched continuous adventitious sounds caused by airway narrowing. Wheezing is a sign of an uncontrolled level of asthma. Automatic detection and classification of cough and wheezing is useful in assisting physicians in the diagnosis and monitoring of acute and chronic respiratory diseases such as asthma, acute bronchitis and COPD [11, 12, 16-18]. Grading of asthma control necessitates specifying the rate of

Table 4 Differences between anthropometric data, ACT scores and LEOSound-monitoring in patients with and without wheezing

\begin{tabular}{|c|c|c|c|c|c|}
\hline & \multicolumn{2}{|c|}{ No wheezing $(n=47)$} & \multicolumn{3}{|c|}{ Wheezing $(n=8)$} \\
\hline & Median & Min - Max & Median & Min - Max & $p$-value \\
\hline \multicolumn{6}{|l|}{ Collective of patients } \\
\hline Age [years] & 37 & $20-67$ & 54 & $38-67$ & 0.01 \\
\hline Height $[\mathrm{cm}]$ & 171 & $154-200$ & 164 & $156-182$ & 0.25 \\
\hline Weight [kg] & 76 & $51-136$ & 75 & $55-135$ & 0.94 \\
\hline BMI $\left[\mathrm{kg} / \mathrm{m}^{2}\right]$ & 24.9 & $17.4-47.1$ & 25.1 & $22.0-40.8$ & 0.38 \\
\hline Pack years & 0 & $0-10$ & 0,5 & $0-8$ & 0.58 \\
\hline ACT & 21 & $11-25$ & 14 & $10-22$ & 0.001 \\
\hline \multicolumn{6}{|l|}{ LEOSound-Monitor } \\
\hline & Median & Min. - Max. & Median & Min. - Max. & \\
\hline Cough-Epochs per hour & 0.1 & $0-1.8$ & 0.3 & $0-4.8$ & 0.25 \\
\hline Abs. quantity of coughs & 1 & $0-63$ & 3 & $0-175$ & 0.33 \\
\hline Quantity of coughs p. hour & 0.1 & $0-7.9$ & 0.4 & $0-34.4$ & 0.33 \\
\hline Wheezing-Phases & 0 & $0-0$ & 2.0 & $1.0-5.0$ & - \\
\hline Wheezing-Epochs per hour & 0 & $0-0$ & 2.4 & $1.0-7.4$ & - \\
\hline Wheezing duration [min] & 0 & $0-0$ & 9.5 & $4.0-30.5$ & - \\
\hline Wheezing duration [\%] & 0 & $0-0$ & 2.4 & $0.9-8.1$ & - \\
\hline
\end{tabular}

Statistically significant $p$-values are bold 


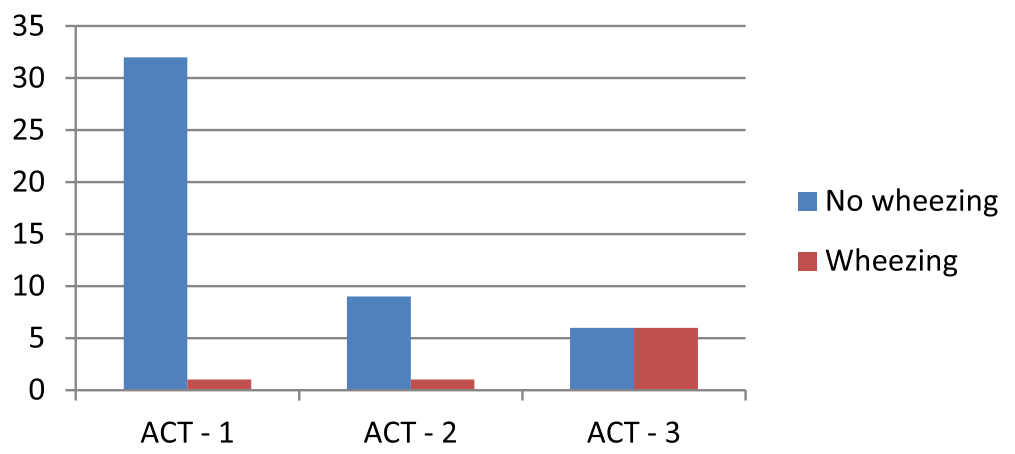

Fig. 3 Nocturnal wheezing and ACT-grouped patients

daytime and nocturnal symptoms. This part of classification concept is used nationally and internationally. However, nocturnal symptoms are difficult to evaluate since patients are unaware of them during sleep. Considering asthma therapy and medication, large multicentre studies spanning multiple countries and years provide valuable information about 15 years of asthma control and care on the ground [4-10]. The results are far from satisfactory. One reason may be the lack of objective evaluation of respiratory symptoms during sleep.

Asthma patients often believe that they have good control of their symptoms. However, control of nocturnal symptoms is overestimated. Up to now there is no way of ensuring an objective symptom control. Ding et al. investigated 1115 patients with mild asthma (average age of 38.4 years) with respect to their asthma control [10]. Nearly half of the patients (40.6\%) exhibited nocturnal symptoms. However, clearly audible wheezing is rare and constitutes the tip of the iceberg. With acoustic long-term recording of breathing sounds, the wheezing, which is normally only heard through the stethoscope, can be analyzed objectively. In the study by Fletcher and Hiles subjective (parent) and objective (recording) data on the frequency of coughing and wheezing varied massively [13]. Understandably, symptoms occurring during sleep are often not perceived by patients.

In addition, Morice et al. presented in their guidelines the need for an objective assessment of respiratory symptoms, like cough and wheezing [19]. So far, evaluation of respiratory symptoms are basically estimated through subjective descriptors. Procedures like manual counting of coughs and wheezing episodes are used in an attempt to obtain a quantitative and objective component. However, for the evaluation of large numbers of patients this approach is impractical. Consequently, there is a necessity for an automated/ objective evaluation of respiratory symptoms [20].

In clinical practice, cough monitors are already in use. After significant progress and development in objective cough monitoring, tools are ready for standard deployment [21]. Nevertheless, long-term monitoring of wheezing has not yet been established in clinical practice.

In this study we only included adults. However, we expect objective monitoring of respiratory symptoms like

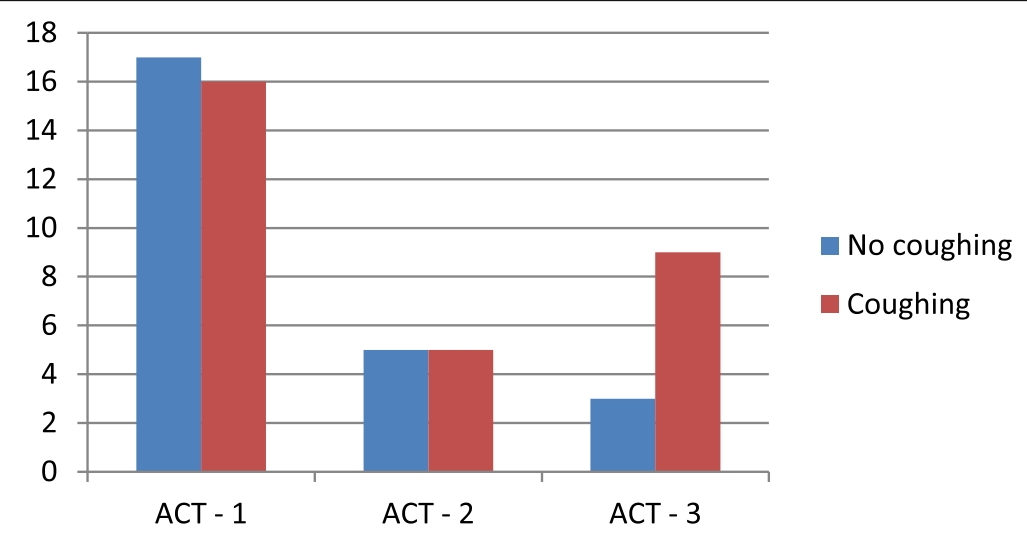

Fig. 4 Coughing and non-coughing patients in ACT-groups 
Table 5 Summary of anthropometric data, ACT scores and LEOSound-monitoring in patients with and without coughing

\begin{tabular}{|c|c|c|c|c|c|}
\hline & \multicolumn{2}{|c|}{ No coughing $(n=25)$} & \multicolumn{3}{|c|}{ Coughing $(n=30)$} \\
\hline & Median & Min - Max & Median & Min - Max & $p$-value \\
\hline \multicolumn{6}{|l|}{ Collective of patients } \\
\hline Age & 33 & $23-63$ & 46 & $20-67$ & 0.06 \\
\hline Height & 170 & $154-200$ & 172 & 156-196 & 0.85 \\
\hline Weight & 78 & $54-136$ & 76 & $51-131$ & 0.83 \\
\hline BMI & 25.7 & $19.1-47.1$ & 24.5 & $17.4-40.2$ & 0.77 \\
\hline Pack years & 0 & $0-10$ & 0.5 & $0-10$ & 0.38 \\
\hline ACT & 22 & $14-25$ & 20 & $10-25$ & 0.06 \\
\hline \multicolumn{6}{|l|}{ LEOSound-Monitor } \\
\hline & Median & Min. - Max. & Median & Min. - Max. & \\
\hline Cough-epochs per hour & 0 & $0-0$ & 0.4 & $0.1-4.8$ & - \\
\hline Absolute quantity of coughs & 0 & $0-0$ & 7.0 & $1-275$ & - \\
\hline Quantity of coughs per hour & 0 & $0-0$ & 0.9 & $0.1-34.4$ & - \\
\hline Wheezing-Phases & 0 & $0-3$ & 0 & $0-5$ & 0.59 \\
\hline Wheezing-Epochs per $\mathrm{h}$ & 0 & $0-7.6$ & 0 & $0-7.3$ & 0.66 \\
\hline Wheezing duration [min] & 0 & $0-30.5$ & 0 & $0-29.0$ & 0.66 \\
\hline Wheezing duration [\%] & 0 & $0-8.1$ & 0 & $0-6.5$ & 0.68 \\
\hline
\end{tabular}

cough and wheezing to have an even greater impact on children. Asthmatic children and adolescents are more likely to show impaired daytime performance compared to healthy controls [22-25]. Night-time asthma results in poorer sleep quality that can also have adverse effects on their efficiency during daytime [20,26]. Reports of children symptoms are often inaccurate or unusable and therefore it becomes essential to objectify respiratory symptoms such as coughing and wheezing, especially during sleep. The acoustic long-term recording of adventitious respiratory sounds is an important addition to the diagnostic spectrum. It is readily available and provides a symptom assessment that is easy to comprehend for, the doctor as well as the patient. Therefore, objective evaluation of respiratory symptoms like cough and wheezing may allow a more accurate and adequate therapy in children with asthma, resulting in a profound effect on children's health.

International multicentre studies such as AIRE (2000) and REALISE (2014) provide information about the reality of asthma treatment and control $[4,5]$. Despite the availability of effective drug therapy, patients with asthma are still insufficiently controlled. By several major studies $50-80 \%$ of all patients were classed as having uncontrolled or just partially controlled status. By implication, only a quarter of the patients were considered to have well-controlled asthma.

In 2014 Price et al. published the REALISE study, in which more than 8000 asthma patients from 11 European countries were surveyed for asthma control [5]. In this study $45 \%$ of patients showed uncontrolled asthma, while $44 \%$ of the patients exhibited at least one acute exacerbation in the previous year, which necessitated oral steroid treatment. $12 \%$ of the patients had to be hospitalized. Over $80 \%$ of respondents rated their asthma as well controlled! In a previous study (AIRE) published by Rabe et al. $2000,80 \%$ of respondents also rated their own asthma control as good, however, objective scrutiny showed that to be the case in only $20 \%$ of those surveyed [4]. While an improvement from 45 to $80 \%$ controlled asthma is a step in the right direction, considerably more improvement has yet to be achieved. Accordingly, in this study only $60 \%$ of the patients scored their asthma as controlled by using the ACT. Moreover, a rating of controlled asthma did not exclude wheezing symptoms during sleep, indicating a lack of subjective asthma control scoring.

The study by Olaguibel et al. revealed that uncontrolled asthma, as assessed by the Asthma Control Questionnaire (ACQ), may be independent of asthma severity [6]. The study included 1363 stable asthmatics with a mean age of 38 years. Only $13.6 \%$ of the patients were considered to have controlled asthma, partially controlled asthma was found in $34.2 \%$ of the patients, and $52.3 \%$ of the patients were deemed to have uncontrolled asthma.

\section{Limitations}

In this study, patients were monitored for only one night. Although asthma has a large symptom variability, and respiratory symptoms may differ from one night to another. Nevertheless, the monitoring for one night 
seems relevant since respiratory symptoms were detected. The aim of the study was to highlight the necessity for and the clinical impact of objective monitoring of respiratory symptoms like cough and wheezing in patients with asthma. Moreover, the sample size of only 55 patients is arguably a limitation of this study. A larger sample size may provide more solid evidence. However, analysis and statistical calculation of our data already showed an appropriate application of this study with respect to 55 patients.

\section{Conclusion}

In our opinion, cough and wheezing during sleep have a direct impact on sleep and quality of life in patients with asthma. Consequently, for the assessment and evaluation of wheezing and cough events, objective approaches like respiratory sound monitoring seem most appropriate. This study presented that a device for long-term monitoring of respiratory sounds is a helpful tool to monitor time course of cough and especially wheezing in patients with obstructive respiratory diseases. Generally, patients may not necessarily notice the respiratory symptoms during sleep. Therefore, the objective evaluation may have a huge clinical impact by adjusting and improving the therapy according to the respiratory symptoms. Moreover, this study only focused on adults whereas the objective evaluation of respiratory symptoms seems to have even more profound relevance on children's health. Especially small children are not as able as older patients to notice and report their respiratory symptoms. This, further research including children may demonstrate. In addition, polysomnographic research may elucidate the impact of sleeping behavior in wheezing and nonwheezing patients on daytime performance and productivity.

\section{Abbreviations \\ ACT: Asthma control test; AVG: Average; BMI: Body mass index; GINA: Global initiative for asthma; PY: Pack years; ICS: Inhaled corticosteroid; LABA: Long acting beta-sympathomimetic agonist; SABA: Short acting beta- sympathomimetic agonist; LAMA: Long acting muscarinic antagonist; SAMA: Short acting muscarinic antagonist; SD: Standard deviation}

\section{Acknowledgements}

We would like to thank Dr Regina Conradt, Cambridge, for revising the language of the manuscript.

\section{Authors' contributions}

JD gathered a part of the data and analysed it. EK gathered a part of the data and analysed it. WC performed the statistic calculations. $\mathrm{OH}$ coordinated the study. AW was a contributor in writing the manuscript. KS participated in the analysis of data. NK participated in the analysis of data. VG took part in interpreting the data. TG helped recruiting the study cohort of patients. UK was a major contributor in writing the manuscript. All authors read and approved the final manuscript.

\section{Funding}

The participation took place on a voluntary base. There was no funding. The Philipps-University of Marburg provided the Hard- and Software (LEOSound-
Monitor and LEOSound-Analyzer). Open Access funding enabled and organized by Projekt DEAL.

\section{Availability of data and materials}

The datasets generated and analysed during the current study are available from the corresponding author on reasonable request.

\section{Ethics approval and consent to participate}

The study was approved by the Ethics Committee of the Philipps University of Marburg (Az:: 94/18). Chairman was Prof. Dr. med. Gerd Richter, corresponding e-mail address:ethikkom@staff.uni-marburg.de

\section{Consent for publication}

Consent for publication are obtained for all included patients.

\section{Competing interests}

The authors declare that they have no competing interests.

\section{Author details}

${ }^{1}$ Department of Internal Medicine, Division of Pneumology, Intensive Care and Sleep Medicine, Hospital of the University of Marburg, Baldingerstrasse 1, 35033 Marburg, Germany. ${ }^{2}$ Thora Tech GmbH, Gießen, Germany. ${ }^{3}$ University of Applied Sciences, Faculty of Health Sciences, Gießen, Germany.

Received: 4 June 2020 Accepted: 9 September 2020

Published online: 23 September 2020

\section{References}

1. World Health Organisation. Global surveillance, prevention and control of chronic respiratory diseases: A comprehensive approach. https://www.who. int/gard/publications/GARD\%20Book\%202007.pdf?ua=1. Accessed on Aug 2020

2. Global Initiative for Asthma. GINA report, global strategy for asthma management and prevention updated. 2020. https://ginasthma.org/wpcontent/uploads/2020/06/GINA-2020-report_20_06_04-1-wms.pdf. Accessed on Aug 2020.

3. Nathan RA, et al. Development of the asthma control test: a survey for assessing asthma control. J Allergy Clin Immunol. 2004;113:59-65.

4. Rabe KF, Vermeire PA, Soriano JB, et al. Clinical management of asthma in 1999: the Asthma Insights and Reality in Europe (AIRE) study. Eur Respir J. 2000;16:802-7.

5. Price $D$, Fletcher $M$, van der Molen T. Asthma control and management in 8000 European patients: the REcognise Asthma and LInk to Symptoms and Experience (REALISE) survey. Prim Care Respir Med. 2014;24:14009.

6. Olaguibel JM, Quirce S, Julia B, et al. Measurement of asthma control according to global initiative for asthma guidelines: a comparison with the asthma control questionnaire. Respir Res. 2012:13:50.

7. Caminati M, Bettoncelli G, Magnoni MS, et al. The level of control of mild asthma in general practice: an observational community-based study. J Asthma. 2014;51:91-6.

8. Caminati M, Senna $G$, Segala N, et al. Evaluation of asthma control in the pharmacy: an Italian cross-sectional study. Eur Ann Allergy Clin Immunol. 2017:49:225-30.

9. Chapman KR, Hinds D, Piazza P, et al. Physician perspectives on the burden and management of asthma in six countries: the Global Asthma Physician Survey (GAPS). BMC Pulm Med. 2017;17:153.

10. Ding B, Small M. Disease burden of mild asthma: findings from a crosssectional real-world survey. Adv Ther. 2017:34:1109-27.

11. Koehler U, Brandenburg U, Weissflog A, et al. LEOSound, an innovative procedure for acoustic long-term monitoring of asthma symptoms (wheezing and coughing) in children and adults. Pneumologie. 2014;68: 277-81.

12. Guenter K, Cassel W, Hildebrandt O, et al. Control of respiratory symptoms during sleep in patients with stable bronchial asthma. Dtsch Med Wochenschr. 2018:143:159-64.

13. Fletcher M, Hiles D. Continuing discrepancy between patient perception of asthma control and real-world symptoms: a quantitative online survey of 1083 adults with asthma from the UK. Prim Care Respir J. 2013;22:431-8.

14. Gross V Scholtes M, Sohrabi K et al. Validation of the LEOSound-monitor for standardized detection of cough and wheezing in children. Worldsleep 
$20157^{\text {th }}$ World Congress of the World Sleep Federation hosted by ESRS, Istanbul, 2015 TR; Abstract book 143.

15. Braghiroli A, Braido F, Piraino A, Rogliani P, Santus P, Scichilone N. Day and night control of copd and role of pharmacotherapy: a review. Int J Chron Obstruct Pulmon Dis. 2020;15:1269-85.

16. Koehler $\mathrm{U}$, Hildebrandt $\mathrm{O}$, Fischer $\mathrm{P}$, et al. Time course of nocturnal cough and wheezing in children with acute bronchitis monitored by lung sound analysis. Eur J Pediatr. 2019;178:1385-94.

17. Kroenig J, Hildebrandt $\mathrm{O}$, Weissflog $\mathrm{A}$, et al. Long-term recording of nighttime respiratory symptoms in patients with stable COPD II-IV. COPD. 2017; 14:498-503.

18. Fischer P, Gross V, Kroenig J, et al. Description of nighttime cough epochs in patients with stable COPD GOLD II-IV. Int J Chron Obstruct Pulmon Dis. 2018;13:1071-8.

19. Morice AH, Fontana GA, Belvisi MG, Birring SS, Chung KF, Dicpinigaitis PV, Kastelik JA, McGarvey LP, Smith JA, Tatar M, Widdicomb J. ERS guidelines on the assessment of cough. Eur Respir J. 2007;29:1256-76.

20. Banasiak NC. Understanding the relationship between asthma and sleep in the pediatric population. J Pediatr Health Care. 2016;30:546-50.

21. Spinou A. Surinder $S$ BirringAn update on measurement and monitoring of cough: what are the important study endpoints? J Thorac Dis. 2014;6(Suppl 7):S728-34.

22. Desager KN, Nelen V, Weyler JJ, et al. Sleep disturbances and daytime symptoms in wheezing school-aged children. J Sleep Res. 2005;14:77-82.

23. Diette GB, Markson L, Skinner EA, et al. Nocturnal asthma in children affects school attendance, school performance, and parents' work attendance. Arch Pediatr Adolesc Med. 2000;154:923-8.

24. Nilsson $\mathrm{S}$, Ödlin $\mathrm{M}$, Andersson $\mathrm{N}$, et al. Does asthma affect school performance in adolescents? Results from the Swedish population-based birth cohort BAMSE. Pediatr Allergy Immunol. 2018;29:174-9.

25. Lozier MJ, Zahran HS, Bailey CM. Assessing health outcomes, quality of life, and healthcare use among school-age children with asthma. J Asthma. 2018:9:1-8.

26. Khan WH, Mohsenin V, D'Ambrosio CM. Sleep in asthma. Clin Chest Med. 2014;35:483-93.

\section{Publisher's Note}

Springer Nature remains neutral with regard to jurisdictional claims in published maps and institutional affiliations.

Ready to submit your research? Choose BMC and benefit from:

- fast, convenient online submission

- thorough peer review by experienced researchers in your field

- rapid publication on acceptance

- support for research data, including large and complex data types

- gold Open Access which fosters wider collaboration and increased citations

- maximum visibility for your research: over $100 \mathrm{M}$ website views per year

At $\mathrm{BMC}$, research is always in progress.

Learn more biomedcentral.com/submissions 